\title{
Lead-lag effects between Brent Crude Futures and its respective spot prices
}

Diego Garcia Angelico' - Univer. Estadual de Campinas - Instituto de Economia - Dep. de Teoria Econômica

ABSTRACT This article aims the analyses of the causality and temporal precedence relationships between the spot and futures prices of Brent oil, those last ones inherent to financial markets. In order to achieve this objective, the main tools used were: Johansen cointegration test; Granger causality/Block Exogeneity Wald test (GCBEW); generalized impulse response function and variance decomposition of forecast errors, those three last ones were estimated based in a Vector Error Correction Model (VEC), adjusted to the analyzed variables. The results indicated that, for the stipulated period, there was a pricing lightweight leadership from the futures contracts to the prices of spot market. However, as a conclusion of the article, the understanding is that this small difference, calculated in several econometric tools, cannot be considered enough to indicate that the Brent oil future market would be distorting its respective spot prices, despite the economic fundamentals of the physical market, such as production, consumption and stockpiling processes. Therefore, management decisions in industries exposed to crude oil prices should be aware of both physical and future markets' prospections.

Keywords Brent oil. Future markets. VEC models. Lead-lag effects. 


\section{INTRODUTION}

The intense increase in commodities prices since the beginning of the 2000s years, as well the price volatility and the several reorientations in its price tendencies since the outbreak of the 2008 global financial crisis, have been one of the main concerns in production engineering, since the manufacturing industries use several commodities as input for its production process. The industries specialized in selling commodities have been facing the same concern about these price dynamics over the past years.

In this context, the future markets, which highlights the crude oil one, have been developing increasingly, with a greater number of contracts traded over the years (INTERCONTINENTALEXCHANGE INC., 2016). As both commercial and financial agents have mutual interest at future prices of crude oil, the specialized media has been calling attention for what they consider excess of speculation at future markets, a movement that can cause distortion in commodity prices in relation to its economic fundamentals, such as supply, demand and stockpiling processes.

The main reasons on which such accusation are based are, especially: i) the drop trend of the American dollar against other major currencies that occurred in the last decade; ii) the excess of liquidity and low interest rate of American dollar in the post crisis period, due to, among other factors, the Quantative Easing monetary policy implemented by the Federal Reserve Bank (TRADING ECONOMICS, 2016). Some analysts infer that this excess of liquidity has may been allocated in future markets, and among them, the Brent crude oil one, taking advantage of the devaluation of American dollar and contributing for distortions in oil prices.

Between all instruments and commodities traded at this particular market, the crude oil future contracts stand out, for the reason that it is the most traded commodity all over the world, and one of the main inputs of global economy (CME GROUP, 2016). From all future oil contracts traded nowadays, the Brent Crude Futures stand out globally, as its prices are reference for the pricing process of about two thirds of the global oil supply. These contracts are traded at ICE Futures Europe and are quoted by the American dollar (INTERCONTINENTALEXCHANGE INC., 2016).

The aim of this paper is to analyze the pricing relations between the Brent crude spot prices and its respective future contracts, traded at ICE Futures Europe, in order to verify if there is a temporal precedence between them, and thus, to infer about the financial market impact over this commodity spot prices, and vice-versa. In addition, the objective is to check the possibility of existence of an excess of speculation at Brent crude oil future market in the last decade and in the beginning of this new one. 
It is understood that this study is extremely important for management and engineering concerns, since the existence of interference by futures markets in the pricing dynamics can potentially affect several production processes that have crude oil as a manufacturing input and/or as a selling commodity. Besides this, managers in industries that have some relation to crude oil can engage in financial operations to provide hedge against any price volatility and/ or distortion caused by speculators, which in turn can help smooth the production of oil and several products that have this commodity as manufacturing input. Having been told, this study aims to provide evidence to support these management and engineering dilemmas.

The remain of the paper is divided as follows: a literature review about crude oil and general future markets and connections between different financial assets is presented in Sections 2; a brief overview on the physical oil markets is presented in Section 3; the data collected and econometric procedures applied in the paper are discussed in Section 4; the main results and discussions are presented in Section 5, being followed by the main final consideration, in Section 6.

\section{LITERATURE REVIEW}

Several researches aim the exploration of existing relations between different markets, by the use of several econometric instruments. By means of the developed techniques at this field, it is possible to identify leader markets/assets in terms of pricing transmission, and consequent lagged variables. Thus, there is an extensive range of researches about the dynamic of pricing transmission between different markets, which can be used for modeling and forecast of economic variables.

Till and Eagleeye (2009) established a research to evaluate if there is excess of speculation at future and option markets of WTI crude oil, by the use of T index. The authors takes into account short and long term positions of hedgers and the contracts launched by financial agents in order to face this hedging demand. Under this metric, the authors concluded that there was not evidence of speculation excess at the complex of financial derivatives of crude oil, although the T index has achieved its peak between the summers of 2007 and 2008, which was a period marked by great valorization of crude oil prices. It is noteworthy that the authors did not examine the comportment of futures-spreading in their analyses.

Nicolau and Palomba (2015) resorted to recursive bivariate VAR models to establish the existence of prediction of the futures price conditional on the prediction of the spot price, and vice-versa, for crude oil and natural gas commodities. For the period between 1997 to 2014, the authors demonstrated the existence of cointegration between the spot and future prices for these two commodities. For the case of crude oil, the cointegration and causality depended on the maturity of the future contracts and a weak exogeneity operated in these relations. The authors also established that posterior to the financial crisis in 2008, investment and hedge strategies in crude oil future markets caused a rise in its spot prices, based on the Granger causality tests. 
Chang and Lee (2015) used the method wavelet coherency analysis in time - frequency domain to demonstrate that there was a long run cointegration between spot and future prices of WTI crude oil between 1986 and 2014. The VEC model used by the authors established that the dynamic relation between spot and future prices was stronger for future short run contracts. The evidence established by the authors also showed that investments and hedge strategies significantly contributed to the structural change occurred in oil prices during the 1990 decade.

Using daily data for the period between 1997 to 2014, Mishra and Smyth (2016) estimated prevision models for the Henry Hub natural gas spot prices and established that future markets were not good forecasters for its respective spot prices. According to the authors, this lack of predictability was due to the heteroscedasticity in the series, which in turn, stimulates profitable trading in the future market. The authors emphasized the need to accommodate heteroscedasticity before applying unit root tests, besides indicating that the lack of predictability between the series is an evidence that the future market is poorly regulated.

Campos et al. (2008) researched the existing relations between different Brazilian spot producers of cattle, besides the market Bolsa de Mercadorias \& Futuros (BM\&F). By treating of multiple variables, the authors applied the Johansen cointegration formula, which one indicated the existence of long term relations between all producer spots and BM\&F. The Granger exogeneity and causality tests indicated a great evidence of pricing lead at BM\&F.

Bergman and Vartanian (2010) studied the relations between Petrobras ordinary stocks (PETR3), traded at BM\&FBovespa, and its respective ADRs, traded at New York Securities Exchange. The Johansen cointegration and Granger causality methodologies indicated, respectively, long term balance and bicausality relations, for the stipulated period of time. The Wald Exogeneity Test accomplished for the variables established that the ADR is relatively more exogenous than the ordinary stock traded at BM\&FBovespa, despite the fact that the impulse-response function confirmed the presence of simultaneity at the stocks pricing transmission. Lastly, by the use of copulas methodology, the authors concluded that extreme negative events at the markets, so called crashes, cause more significant variations in stocks than the positive events do.

Guillén et al. (2012) studied the existing relations between funding, credit and compulsory of Brazilian banks, before and after the subprime crisis. As analysis tools, the authors estimated an autoregressive vector model, impulse response functions and variance decomposition of forecast errors. By the use of variance decomposition of forecast errors, the authors could conclude that, before the financial crisis, the variables credit and funding were independent, and the influence of compulsory was low and constant. However, after the subprime collapse, the variables credit and compulsory affected the variance of funding, and credit only depended on variable funding in periods superior to two months.

As conclusion, the authors understood that before the crisis, the Brazilian banks had autonomy to operate credit portfolios, although this management was changed after the collapse, because in this new period the variable funding affected the credit growth, changing the liquidity dynamics of these financial institutions. 


\section{THE PHYSICAL OIL MARKETS - A BRIEF OVERVIEW}

The U.S. Energy Information Administration (EIA, 2016) published a research that contemplates the relation of West Texas Intermediate (WTI) oil prices with the dynamics of the physical market, such as production, consumption and stockpiling processes. As the prices of this particular oil have always been synchronized with the Brent crude oil ones, it can be affirmed that market conjunctures affect both commodities similarly. Therefore, this research served as a basis to establish an overview of market conditions of general crude oil over the last ten years.

In relation to oil global production, it is interesting to divide it between the countries belonging to the Organization of Petroleum Exporting Countries (OPEC) block and the other nations. In relation to these nominated as non OPEC countries, it can be observed that its productions presented a very low, and even decreasing in some quarters, growth during the years of 2006, 2007 and 2008, period that the crude oil prices presented great appreciation. As a consequence of this productive reduction, the OPEC countries were forced to reduce its idle capacity, from 2003 to 2008, which may have climbed the risk premium of crude oil prices, since these countries were more inert to abrupt changes of supply and demand market conditions (EIA, 2016).

This research has also categorized the demand structure of countries belonging to the Organization for Economic Co-operation and Development (OECD) and the other nations, since each category represents about $50 \%$ of global consumption of crude oil. In relation to the first group, formed by countries which economies are already at a certain level of development maturity, the consumption of crude oil decreased during the decade 2000-2010. These economies were more sensitive to price increases of crude oil, since the consumption decreased intensively from 2006 to 2009, which was a period marked by a great appreciation of this commodity prices. Factors as more advanced sectors of transportations and services, high taxes and absence of subsidies for fossil fuels caused, in general, a slower growth of crude oil consumption in these countries, for the stipulated period.

The non OECD countries presented a different comportment during the last decade, since the growth of this commodity consumption was about $40 \%$. The rate of economic growth of such economies strongly affects the crude oil prices, for the reason that a large portion of these economies belongs to the industrial sector, which is a large consumer of crude oil. Besides, there is a lot of room to increase the transportation of goods and people in these economies (EIA, 2016).

Lastly, the control of final prices of fuels derived from crude oil in some of these economies contributes to sustain this commodity demand, increasing its prices in the international markets. For these reasons, during the period of great appreciation of crude oil prices (20052008), the consumption of this commodity in these countries continued positive, differently from the economies belonging to the OECD block. 
The research has also contemplated the dynamic of stockpiling processes in the OECD countries. If the expectations, for the future, are rising prices of crude oil, either by increasing demand or reducing supply, the producers will have incentives to form stockpiles. Therefore, a greater immobilization of crude oil by these agents will decrease the respective current supply, increasing the spot prices. However, when there is a rise in prices above the potential level, the market participants understand that there is a gap between production and consumption, and reduce their stockpiles previously formed. So, when there was a sudden increase of demand, or reduction of supply, the previously formed stockpiles were consumed and the spot prices increased (EIA, 2016).

\section{METHOD}

\subsection{Data}

The series used in this paper were the future and spot prices of Brent crude oil, respectively collected in the InternationalExchange Inc. (2016) and U.S. Energy Information Administration (2016) databases. The series are between 01/03/2000 and 09/30/2011, in a daily basis, containing 2,995 observations each one. All values were deflated by the U.S. Consumer Price Index (CPI), available at Trading Economics (2016) for the last month of the series, September/2011. The softwares used to run the econometric procedures were EViews 7.0 and GRETL, beyond the Microsoft Excel spreadsheets.

\subsection{Cointegration, Vector Error Correction Model (VEC) and Lead-lag effects}

\subsubsection{Unit root tests}

Firstly, it was necessary to establish the unit root tests for each series, for the reason that the Johansen cointegration test and the Vector Error Correction (VEC) model require that the variables be integrated of the same order (JOHANSEN, 1991). According to Engle and Granger (1987), a series is integrated of order d if this same series can be represented by an Autoregressive Moving Average (ARMA) model and is stationary, invertible and does not have a deterministic component, being $\mathrm{d}$ the necessary number of differentiations to turn it into stationary. 
The unit root tests KPSS (KWIATKOWSKI; PHILLIPS; SCHMIDT; SHIN, 1992) and Augmented Dickey-Fuller (ADF) were used to determine the integration order of the analyzed series. According to Dickey and Fuller (1981), the comportment of a time series is described by the order of the autoregressive process $p$. Thereby, the ADF test can be Equated in (1). In this case, the hypothesis $\mathrm{H} 0: \gamma=0$ tests the presence of unit root.

$$
\Delta x_{t}=a+\beta_{t}+x_{t-1}+\sum_{t=1}^{p-1} \gamma_{1} \Delta x_{t-1}+\varepsilon_{t}
$$

in which $\lambda_{1}=\sum_{j=i+1}^{p} \rho_{j}$ and $\gamma=\sum_{t=1}^{p} p_{i}-1$.

Differently from ADF test, the KPSS one assumes the series stationary as null hypothesis, as established in (2):

$$
L M=T^{-2} \sum_{t=1}^{T} \frac{s_{t}^{2}}{s^{2}(l)}
$$

in which $S_{t}$ is the partial sum of the deviations of residuals in relation to the sample average, $l$ is one parameter used to soften the sample $\mathrm{AC}, \mathrm{S}^{2}(\mathrm{l})$ is the approximate long term variance and $\mathrm{T}$ is the total number of observations.

For both tests, the selection of lags of each one was held based on the auto-correlation and partial auto-correlation functions (ACF and PACF, respectively). The Akaike Criterion Information (AIC) and Schwartz Bayesian Criterion (SBC) were also used, which ones can be represented, respectively, in (3) and (4):

$$
\begin{gathered}
A I C=\mathrm{TI} n(s q r)+2 n \\
S B C=\mathrm{TI} n(s q r)+n \mathrm{I} n(\mathrm{~T})
\end{gathered}
$$

\subsubsection{Cointegration test}

According to Engle and Granger (1987), if a stationary time series of order zero, I(0), can be generated by a linear combination between two non stationary and integrated of same order variables, these ones can be considered cointegrated. Therefore, the comovements occurred between these variables generate an Error Correction Mechanism (ECM) of the short term random deviations that need to be included in the model. Thus, it must be estimated a VEC model, which consists in an Error Correction VAR model. 
A system of economic variables will be in long term balance if $b_{1} x_{1 t}+b_{2} x_{2 t}+\ldots b_{n} x_{n t}=0$. Thus, balance errors are the deviations from long term balance, represented by $e_{t}=b^{\prime} X_{t}$, which can be considered stationary (ENGLE; GRANGER, 1987).

There will be a cointegration of order $b, d$ or $x_{t} \sim C I(d, b)$ between the components of the vector $\mathrm{X}_{\mathrm{t}}=\left(\mathrm{x}_{1,}, \mathrm{X}_{2}, \ldots \mathrm{x}_{\mathrm{nt}}\right)$ if all these components are integrated of order $\mathrm{d}$, and also if there is a vector $b=\left(b_{1}, b_{2}, \ldots b_{n}\right)$ in such a way that there is a linear combination $b^{\prime}=\left(b_{1} x_{1 t}+b_{2} x_{2 t}+\right.$ $\left.\ldots b_{n} x_{n t}\right)$ integrated of order (d-b) in which $b>0$. Therefore, the integration order of the linear residual combination $\left(\mathrm{Z}_{\mathrm{t}}\right)$ of the model will be lower than the ones observed for the original variables (ENGLE; GRANGER, 1987).

In order to test the presence of cointegration in a series, the Johansen methodology is valid. Consider the following model in (5) (ENDERS; GRANGER, 1998):

$$
\Delta y_{t}=\alpha_{0}+\alpha y_{t-1}+\sum_{i=1}^{p} \alpha_{i} \Delta y_{t-i}+\varepsilon_{t}
$$

in which $\alpha=-\left(I-\sum_{i=1}^{p} A_{i}\right)$ and $\alpha_{i}=-\sum_{j=i+1}^{p} A_{j}$.

The number of cointegration vectors ( $\mathrm{r}$ ) is determined by maximum eigenvalue and trace statistics, respectively represented in (6) and (7) (ENDERS; GRANGER, 1998):

$$
\begin{array}{r}
\lambda_{\max }(r, r+1)=-T \sum_{i=r+1}^{n} \operatorname{In}\left(1-\lambda_{r+1}\right) \\
\lambda_{\text {trace }}(r)=-T \sum_{i=r+1}^{n} \operatorname{In}\left(1-\lambda_{i}\right)
\end{array}
$$

\subsubsection{VAR and VEC Models}

In case the variables have a long term balance relation, a VEC model can be estimated, or equivalently, an Error Correction VAR model. The VAR model is appropriate if the $\mathrm{n}$ variables belonging to $X_{t}$ vector are stationary. However, if these variables are not stationary and if there are not cointegration relations, the VAR model must run the series in the first difference. Generically, a VAR model can be established in (8) (PESARAN; SHIN, 1998):

$$
X_{t}=\theta D+G_{1} X_{t-1}+G_{2} X_{t-2}+\ldots G_{p} X_{t-p}+\varepsilon_{t}
$$

in which $\theta$ is the coefficient of deterministic variables $D$; $D$ represents the deterministic variables; $G_{i}$ is the matrix nxn of coefficients with elements $g_{j k, i}$ of lagged variables $X_{t-i} ; e_{t}$ is the independent and auto-correlated error vector, with normal and identical distribution. 
However, according to Enders and Falk (1999), the cointegrated variables suffer deviations, in short term, from the long term balance relation. Therefore, the adjustment cannot be determined without a dynamic specification of the model. For this reason, the error correction model is used, aiming the correction of the previous period deviation. Thus, if there are cointegration equations between the variables, being these non stationary, the Error Correction VAR model (VEC) must be estimated, which can be denoted in (9):

$$
\Delta X_{t}=\theta+\Gamma_{1} \Delta X_{t-1}+\Gamma_{2} \Delta X_{t-2}+\ldots+\Gamma_{p-1} \Delta X_{t-p-1}+\Pi X_{t-1}+\varepsilon_{t}
$$

in which $\Pi=\alpha \beta^{\prime}$ is a matrix with parameters $\mathrm{nxn}$, which is factored into two products. The $\beta$ ' is a cointegration vector that represents the presence of transformed stationary series $\left(\mathrm{z}_{\mathrm{t}}=\beta^{\prime} \mathrm{X}_{\mathrm{t}}\right)$ and $\mathrm{h}$ cointegration relations. The $\alpha$ is the matrix of parameters that determines the rate adjustment of elements $\mathrm{X}_{\mathrm{t}}$ in response to the lagged deviations $\left(\mathrm{Z}_{\mathrm{t}-1}\right)$.

\subsubsection{Instruments of Lead-lag Effects}

According to Enders and Granger (1998), the Granger Causality/Block Exogeneity Wald test (GCBEW) can detect if the lags of a variable can Granger cause other ones of a VAR system, besides indicating the relative exogeneity of each one. Thus, the null hypothesis consists in the exclusion of all lags of the tested variable of the VAR system equations. This test equation can be represented in (10):

$$
(T-3 p-1)\left(\log \left|\Sigma_{r e}\right|-\log \left|\Sigma_{u n}\right|\right) \sim \chi^{2}
$$

in which $\sum_{u n}$ is the variance/covariance matrix of unrestricted VAR system; $\Sigma_{r e}$ is the variance/covariance matrix of the restricted system when the lag of one variable is excluded from the VAR system; $p$ is the number of lags of the excluded variable from the VAR system; $\mathrm{T}$ is the number of observations.

According to Granger (1969), one variable $\mathrm{Y}$ is caused by one variable $\mathrm{X}$ if a forecast of $\mathrm{Y}$ is statistically more significant if the lagged values of $\mathrm{X}$ are included over the lagged values of Y. Therefore, the Granger causality test must estimate the following regressions, established in (11) and (12):

$$
\begin{aligned}
& X_{t}=\Sigma \alpha_{i} Y_{t-1}+\Sigma b_{i} X_{t-1}+\mu_{1 t} \\
& Y_{t}=\Sigma c_{i} Y_{t-1}+\Sigma d_{i} X_{t-1}+\mu_{2 t}
\end{aligned}
$$

The test results lead to four distinct scenarios: unilateral causality from $\mathrm{Y}$ to $\mathrm{X}$; unilateral causality from X to Y; bicausality or simultaneity and independence. 
The impulse response function presents the comportment variations of variables of a VAR model in response to shocks or changes caused by residual variables. In simple, an impulse response function establishes an effect over time of a shock in the expected future values in the variables of a VAR system. Generally, this function approach is used according to Cholesky decomposition, in which the order of the estimated variables in the VAR model must not be underestimated.

According to Pesaran and Shin (1998), the generalized impulse response function does not have the restriction of variable ordination, and there are only coincidences with traditional functions in case of shocks in the first equation of the VAR, for a variance matrix of non diagonal errors. Therefore, differently from traditional impulse response function, the generalized one imposes innovations in only one element $\varepsilon_{\mathrm{t}}$, and the effects of the other shocks are obtained based in a presumed distribution of errors, Equated in (13) (PESARAN; SHIN, 1998):

$$
G I_{x}\left(n, \delta_{j}, \Omega_{t-1}\right)=E\left(x_{t+n} \mid \varepsilon_{j t=} \delta_{j}, \Omega_{t-1}\right)-E\left(x_{t+n} \mid \Omega_{t-1}\right)
$$

Therefore, it can be assumed $\mathrm{GI}_{\mathrm{x}}\left(\mathrm{n}, \delta, \Omega_{\mathrm{t}-\mathrm{l}}\right)=\mathrm{A}_{\mathrm{n}} \delta$, which is dependent of the shock composition defined by $\sqrt{ }$ and independent from $\Omega_{\mathrm{t}-1}$.

Assuming a multivariate normal distribution of $\varepsilon_{\mathrm{t}}$, the equation can be established in (14):

$$
E\left(\varepsilon_{t} \mid \varepsilon_{j t}=\delta_{j}\right)=\left(\sigma_{1 j}, \sigma_{2 j}, \ldots, \sigma_{m j}\right)^{\prime} \sigma_{j j}^{-1}=\sum e_{j} \sigma_{j j}^{-1} \delta_{j}
$$

Defining $\delta_{j}=\sqrt{\sigma_{i j}}$, in other words, a shock of one standard deviation, the impulse response function, with scale, can be represented in (15):

$$
\psi_{j}^{g}(n)=\sigma_{i j}^{-0,5} A_{n} \sum e_{j}
$$

Therefore, the impulse response functions measure the effects of a standard deviation shock of jth equation errors in time $t$ in the expected values of $x$ in time $t+n$.

The variance decomposition of forecast errors allows inferring about the effect that a non early shock over certain variable has over itself and over the other variables belonging to the system (GRANGER; TERASVIRTA, 1993). In other words, this method consists in separate the variation of each endogenous variable in the contributions of the several shocks of the variables belonging to VAR, demonstrating the relative importance of each random innovation that affects the variables of the auto-regressive vector system.

Assuming the objective of performing the forecast of conditional values $\mathrm{x}_{\mathrm{t}+1} x_{t+1}$ to the observed values $x_{t}$, the Equation in (16) is valid (GRANGER; TERASVIRTA, 1993):

$$
x_{t}=A_{0}+A_{1} x_{t-1}+e_{t}
$$


Taking the conditional expectation of $\mathrm{x}_{\mathrm{t}+\mathrm{n}}$ and performing the translation to the future $\mathrm{n}$ period ahead, the equation can be established in (17):

$$
E\left(x_{t+n}\right)=\left(I+A_{1}+A_{1}^{2}+A_{1}^{3}+\ldots+A_{1}^{n}\right) A_{0}+A_{1}^{n} x_{t}
$$

Therefore, the forecast error $\mathrm{n}$ steps ahead can be Equated in (18):

$$
x_{t+2}-E\left(x_{t+2}\right)=A_{1}^{n-1} e_{t+1}+\ldots+A_{1}^{2} e_{t+n+2}+A_{1} e_{t+n+1}+e_{t+2}
$$

Given that the forecast error can be considered in terms of Vector Moving Averages (VMA), its respective properties can be described in terms of shocks $\varepsilon_{t}$ sequence. Thus, the variance of forecast error $\mathrm{n}$ steps ahead is determined in (19):

$$
\sigma_{x}(n)^{2}=\sigma_{x}^{2}\left[\phi_{11}(0)^{2}+\phi_{11}(1)^{2}+\ldots+\phi_{11}(n-1)^{2}\right]+\sigma_{y}^{2}\left[\phi_{12}(0)^{2}+\phi_{12}(1)^{2}+\ldots+\phi_{12}(n-1)^{2}\right]
$$

In terms of causality analysis, it is valid the identification of the movement ratio in the sequence of error variance, which is assigned to each of the primitive shocks in $\varepsilon_{\mathrm{xt}}$ and $\varepsilon_{\mathrm{y}}$, respectively represented in (20) and (21):

$$
\begin{aligned}
& \frac{\sigma_{x}^{2}\left[\phi_{11}(0)^{2}+\phi_{11}(1)^{2}+\ldots+\phi_{11}(n-1)^{2}\right]}{\sigma_{x}(n)^{2}} \\
& \frac{\sigma_{y}^{2}\left[\phi_{12}(0)^{2}+\phi_{12}(1)^{2}+\ldots+\phi_{12}(n-1)^{2}\right]}{\sigma_{x}(n)^{2}}
\end{aligned}
$$

\section{RESULTS AND DISCUSSIONS}

\subsection{Stationary analysis}

The Figure 1 establishes the spot and future prices of Brent crude oil, traded in American dollars and deflated by Customer Price Index (CPI). Graphically, it is perceived that both series are subjected to the same market movements, demonstrating a strong evidence of cointegration. The series present an uptrend between 2004 and mid 2008, probably caused by the growth of emerging economies and some restrictions in this commodity global supply. After the financial collapse of 2008 , the prices show a new uptrend, partially caused by the fast and invigorating recovery of emerging economies. 
Figure 1 - Deflated spot (left) and future prices of Brent crude oil.
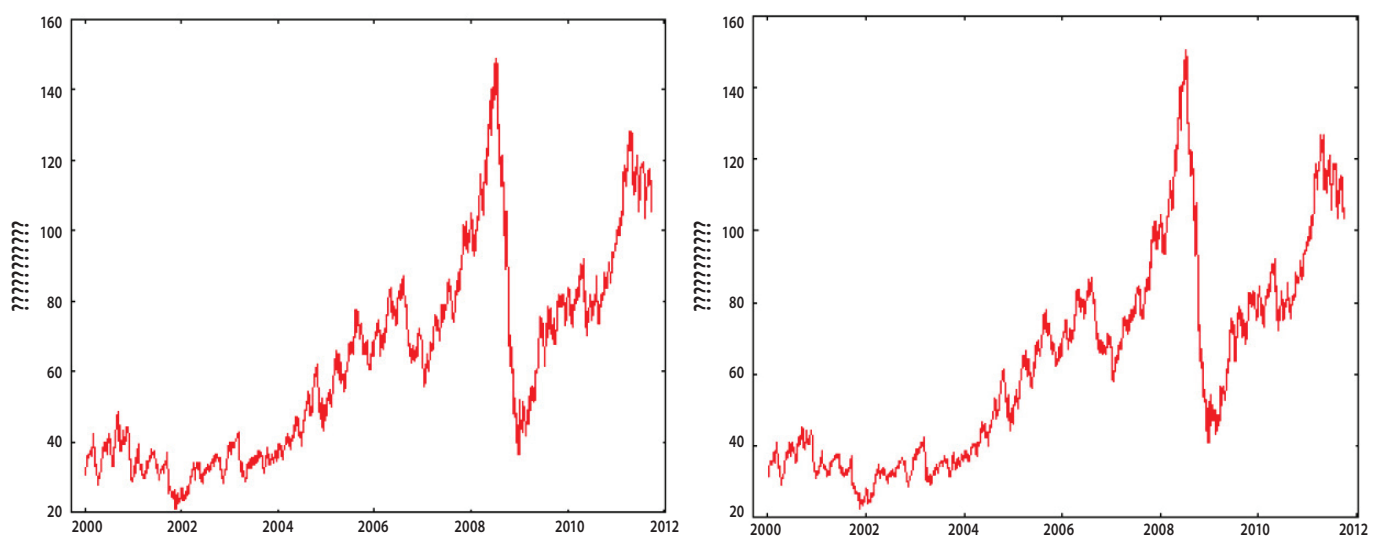

Source: Own elaboration based on U.S. Energy Information Administration, InternationalExchange Inc. (ICE) and Trading Economics databases, 2016.

The Figure 2 establishes the comportment of linearized returns of the deflated spot and future prices, for the same stipulated period. Likewise, the returns present a similar comportment during the whole period, for both analyzed variables. It is noticed that the crude oil prices are extremely volatiles, since the graphical comportment demonstrates a very high conditional variance.

Figure 2 - Linearized returns of spot (left) and future prices of Brent crude oil.
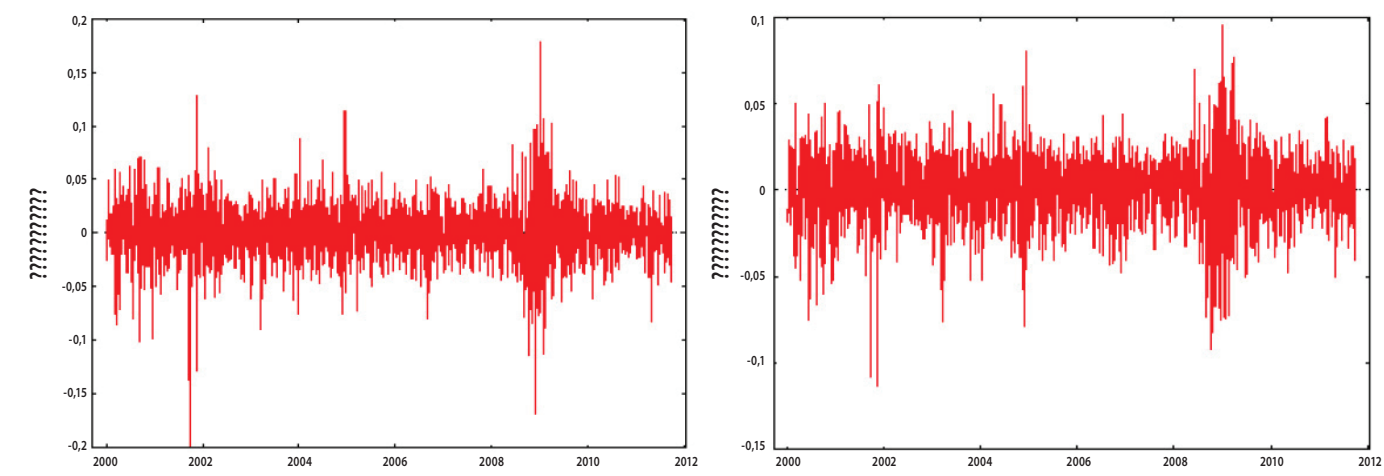

Source: Own elaboration, 2016. 
In this paper, it has been chosen the performance of KPSS and ADF tests, since the first one has as null hypothesis the presence of stationarity in the series, while the second one assumes the existence of unit root as its null hypothesis. Therefore, a joint analysis of both tests brought more certainty to the data diagnosis.

The Table 1 establishes the KPSS tests for deflated and linearized series of future and spot prices of Brent crude oil, in level and its respective returns. It is noticed that, for the series in level, the generated statistics are above the critical values, in other words, in a region of rejection of the stationarity null hypothesis, demonstrating the absence of this comportment for the original series. The linearized returns present the test statistics in a non rejection zone of the null hypothesis, in other words, these series can be considered stationary, to the significance levels of $5 \%$ and $1 \%$.

Table 1 - KPSS unit root test for spot and future prices of Brent crude oil, in level and its respective returns.

\begin{tabular}{cccc}
\hline Variable & Test Statistic & Critical Value (5\%) & Critical Value (1\%) \\
\hline FUT (LEVEL) & 1.83449 & 0.148 & 0.218 \\
\hline FUT (RETURNS) & 0.040007 & 0.461 & 0.743 \\
\hline SPOT (LEVEL) & 1.71689 & 0.148 & 0.218 \\
\hline SPOT (RETURNS) & 0.0330862 & 0.461 & 0.743 \\
\hline
\end{tabular}

Source: Own elaboration, 2016.

The Table 2 establishes the ADF tests for the analyzed series. Observing the generated p-values, the null hypothesis of unit root is not rejected for the series in level, since the values are superior to the significance level of $5 \%$. However, the linearized returns rejected the null hypothesis of unit root, since the respective p-values are inferior to the established significance level, feature of stationary series. The joint analysis of KPSS and ADF tests establishes a strong evidence of stationarity for the linearized returns and presence of unit root in the original series (in level).

Table 2 - ADF unit root test for spot and future prices of Brent crude oil, in level and its respective returns.

\begin{tabular}{cc}
\hline Variable & Asymptotic p-value \\
\hline FUT (LEVEL) & 0.32 \\
\hline FUT (RETURNS) & $2.11 E-25$ \\
\hline SPOT (LEVEL) & 0.2324 \\
\hline SPOT (RETURNS) & $5.91 E-27$ \\
\hline
\end{tabular}

Source: Own elaboration, 2016. 


\subsection{Instruments of Lead-lag Effects}

The Johansen cointegration methodology, as presented in Econometric Procedures, can be viewed in Tables 3 and 4 . The test was estimated with the linearized variables in level, by inserting four lags. As can be observed, both statistics rejected the absence hypothesis of cointegrating vectors between the variables. The trace statistics did not reject the presence hypothesis of, up to a maximum, one cointegrating vector, and the maximum eigenvalue statistics accepts the existence hypothesis of one cointegrating vector, indicating a strong evidence of cointegration between the series.

Table 3 - Trace Statistics of Johansen Cointegration Test for spot and future prices of Brent crude oil.

\begin{tabular}{ccccc}
\hline $\begin{array}{c}\text { Hypothesis } \\
\mathrm{N}^{\circ} \text { of } \mathrm{CE}(\mathrm{s})\end{array}$ & Eigenvalue & $\begin{array}{c}\text { Trace } \\
\text { Statistics }\end{array}$ & $\begin{array}{c}0.05 \\
\text { Critical Value }\end{array}$ & Prob \\
\hline $\mathrm{r}=0$ & 0.031821 & 97.37423 & 15.49471 & 0.0000 \\
\hline $\mathrm{r} \leq 1$ & 0.000647 & 1.910823 & 3.841466 & 0.1669 \\
\hline
\end{tabular}

Source: Own elaboration, 2016.

Table 4 - Maximum Eigenvalue Statistics of Johansen Cointegration Test for spot and future prices of Brent crude oil.

\begin{tabular}{ccccc}
\hline $\begin{array}{c}\text { Hypothesis } \\
\mathrm{N}^{\circ} \text { of CE(s) }\end{array}$ & $\begin{array}{c}\text { Max. Eigenvalue } \\
\text { Eigenvalue }\end{array}$ & Statistics & $\begin{array}{c}0.05 \\
\text { Critical Value }\end{array}$ & Prob \\
\hline $\mathrm{r}=0$ & 0.031821 & 95.46340 & 14.26460 & 0.0000 \\
\hline $\mathrm{r} \leq 1$ & 0.000647 & 1.910823 & 3.841466 & 0.1669 \\
\hline
\end{tabular}

Source: Own elaboration, 2016.

For the reason that the analyzed variables are cointegrated, a VEC (Autoregressive Vectors with Error Correction) model was estimated for the linearized series in level, in order to infer about the procedures of temporal precedence proposed in methodology. The Table 5 presents the calculated criteria for several simulations, demonstrating that the best model was estimated with up to three lags. 
Table 5 - AIC and SBC criteria for lag selection of VEC model.

\begin{tabular}{ccc}
\hline Lags & Akaike Information Criterion (AIC) & Schwarz Bayesian Criterion (SBC) \\
\hline$(1$ 1) & -10.95267 & -10.93239 \\
\hline$(12)$ & -10.96998 & -10.94159 \\
\hline$(13)$ & -10.97967 & -10.94315 \\
\hline$(14)$ & -10.97753 & -10.93288 \\
\hline$(15)$ & -10.97806 & -10.92528 \\
\hline$(16)$ & -10.98107 & -10.92016 \\
\hline$(1$ 7) & -10.98011 & -10.91105 \\
\hline
\end{tabular}

Source: Own elaboration, 2016.

The Table 6 establishes the LM residual auto-correlation test for the VEC model, confirming absence of this comportment for the generated residuals, demonstrating effectiveness in the number of lags inserted.

Table 6 - LM residual auto-correlation test for the VEC model.

\begin{tabular}{ccc}
\hline Lags & LM Statistics & p-value \\
\hline 1 & 0.824142 & 0.9352 \\
\hline 2 & 7.205293 & 0.1254 \\
\hline 3 & 3.292338 & 0.5101 \\
\hline 4 & 2.208150 & 0.6975 \\
\hline 5 & 3.116401 & 0.5385 \\
\hline
\end{tabular}

Source: Own elaboration, 2016.

The Granger Causality/Block Exogeneity Wald (GCBEW) test was estimated for the VEC model variables, according to Table 7. It is perceived, through the estimated probabilities, that there is a bicausality between spot and future prices of Brent crude oil. However, the estimated values of Chi-square statistics establish that the future prices are relatively more exogenous than the spot ones. 
Table 7 - Granger Causality/Block Exogeneity Wald test for VEC model.

\begin{tabular}{ccc|cc} 
& \multicolumn{3}{c}{ Dependent variable } \\
\cline { 2 - 5 } & \multicolumn{2}{c|}{ Spot prices } & \multicolumn{2}{c}{ Future prices } \\
\cline { 2 - 5 } & \multicolumn{2}{c}{ Chi-sq } & Chi-sq & Prob. \\
\hline Spot prices & & 52.29909 & 0.000 \\
\hline Future prices & 80.28513 & 0.000 & & \\
\hline
\end{tabular}

Source: Own elaboration, 2016.

The generalized impulse response functions can be viewed in Figure 3. By the graphical analysis, it is noticed that the response due to one standard deviation shock is superior in the series of spot prices, demonstrating that it is relatively more influenced by future prices than vice-versa, corroborating the results calculated in GCBEW test.

Figure 3 - Generalized impulse response function of the VEC model.
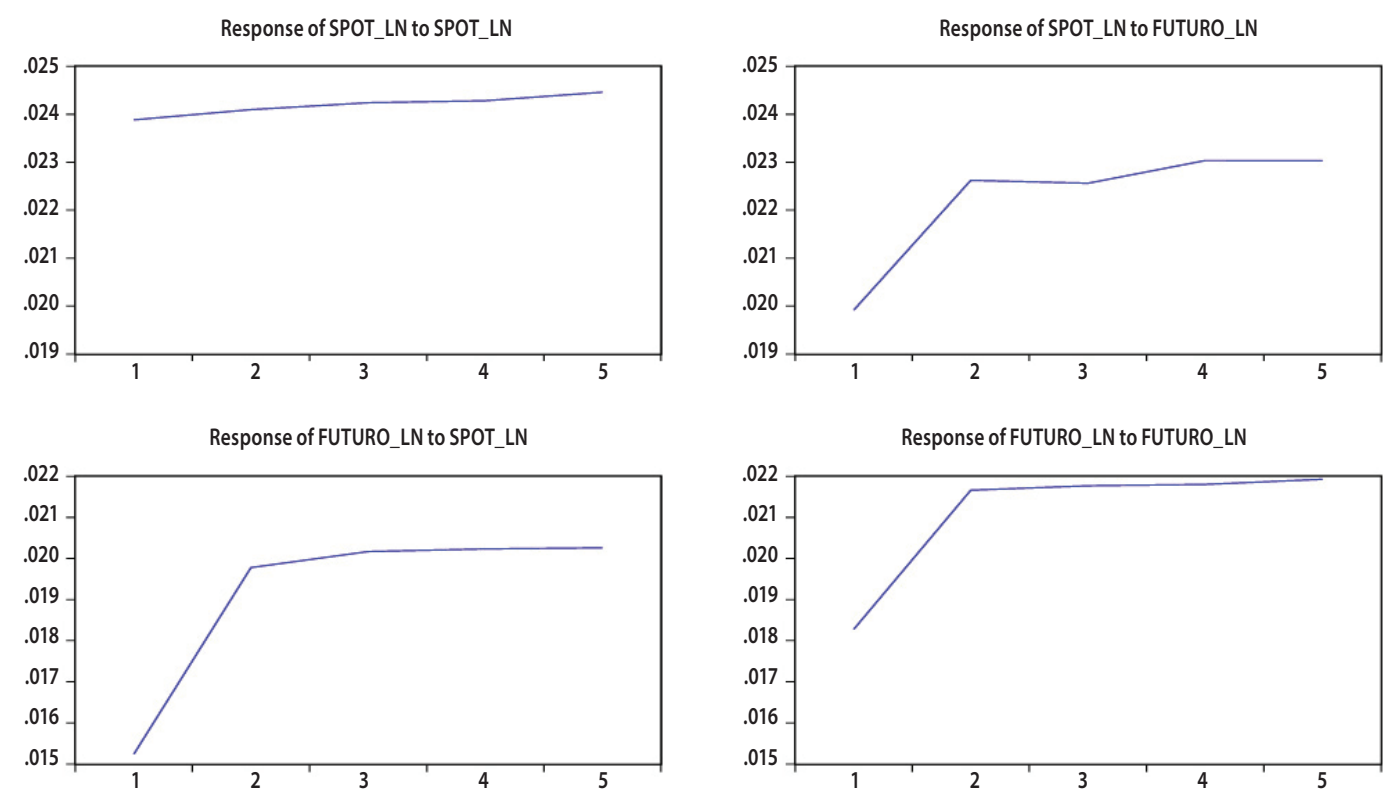

Source: Own elaboration, 2016. 
Similarly, the variance decomposition of forecast errors, at Table 8, demonstrates a slightly higher influence from future prices over spot market. As can be observed, the prices inherent to the future market have a greater weighting at the variance decomposition of forecast errors of spot prices than vice-versa, from the second period onwards (trading days).

Table 8 - Variance decomposition of forecast errors of VEC model.

\begin{tabular}{c|ccc|ccc}
\hline \multicolumn{7}{c}{ Variance decomposition of forecast errors (in \%) } \\
\hline & \multicolumn{3}{c}{ Prices of future Market } & \multicolumn{3}{c}{ Prices of spot Market } \\
\hline Period & Standard error & SPOT & FUTURE & Standard error & FUTURE & SPOT \\
\hline 1 & 0.018277 & 69.54535 & 30.45465 & 0.023884 & 69.54535 & 30.45465 \\
\hline 2 & 0.028513 & 76.70259 & 23.29741 & 0.034237 & 77.51103 & 22.48897 \\
\hline 3 & 0.036059 & 79.23638 & 20.76362 & 0.042166 & 79.73202 & 20.26798 \\
\hline 4 & 0.042302 & 80.45034 & 19.54966 & 0.048918 & 81.40866 & 18.59134 \\
\hline 5 & 0.047781 & 81.03290 & 18.96710 & 0.054899 & 82.23251 & 17.76749 \\
\hline 6 & 0.052740 & 81.54614 & 18.45386 & 0.060200 & 82.95177 & 17.04823 \\
\hline
\end{tabular}

Source: Own elaboration, 2016.

\section{CONCLUSIONS}

This paper aimed to identify if the prices of ICE Brent Future contracts influenced, or even distorted, the spot prices of Brent crude oil in the last decade and in the beginning of this new one, periods marked by intensive increases in crude oil prices. One of the main concerns about this price dynamics refer to the impact that an excess of speculation in financial markets can promote on management decisions related to engineering production in industries exposed to crude oil prices, in the way that this impact can potentially distort price variations due to physical market conditions.

Therefore, the most widespread econometric instruments in literature were used, which ones enable the inference about temporal precedence and leadership, in terms of pricing, between different markets. The Johansen cointegration test, GCBEW test, generalized impulse response function and variance decomposition of forecast errors were estimated, given the fact that the last three ones were estimated using a VEC model adjusted to the analyzed series. Except for the Johansen cointegration test, all instruments indicated a slight superiority from future market to spot prices, in terms of price transmission.

As conclusion, it is understood that this temporal precedence statistically calculated between the series is not enough to infer that there was a price distortion caused by operators of financial markets, since the results of these econometric instruments do not have a high difference between both analyzed series. 
The final understanding is that the price movements of Brent crude oil were both determined by the structures of the physical market and for the conjunctures of the future market for the stipulated period. Despite rejecting the hypothesis that there would be an excess of speculation in future markets, this paper established that the simultaneous price determination between spot and future markets imposes a challenge to engineering production planning in industries exposed to crude oil prices.

In other words, management decisions should be aware about the structure and prospections in both the physical and financial markets. Given the current level of financial globalization, several variables can affect the crude oil prices via the financial markets, which were not analyzed in this paper. As was described in the Section "Literature Review", several financial assets are cointegrated, which rises the links between markets that apparently don't have connection. A future study that analyze the impact of financial variables on crude oil prices is recommended.

\section{REFERENCES}

BERGMAN, D. R.; VARTANIAN, P. R. Integração, causalidade e análise dos eventos extremos entre ações da Petrobras negociadas no mercado brasileiro e ADR no mercado norte-americano. Publicação Interna do Instituto de Matemática, Estatística e Computação Científica da Unicamp. Campinas, 2010.

CAMPOS, S. K.; COSTA, J. S.; SILVA, S. F.; ZILLI, J. B. Análise da cointegração e causalidade dos preços de boi gordo em diferentes praças nas regiões sudeste e centro-oeste do Brasil. Revista de Economia Agrícola, São Paulo, v. 55, n. 2, p. 105-119, 2008.

CHANG, C. P.; LEE, C. C.C. Do oil spot and futures prices move together? Energy Economics, v. 50, p. 379-390, 2015.

CME Group. Available in: <http://www.cmegroup.com/>. Acesso em: 08 fev. 2016.

DICKEY, D.; FULLER, W. Likelihood ratio statistics for autoregressive time series with a unit root. Econometrica, v. 49, n. 4, p. 1057-1072, 1981.

EIA - U.S. Energy Information Administration. Database. Available in: <http://www.eia. gov>. Acesso em: 05 fev. 2016.

ENDERS, W.; FALK, B. Confidence Intervals for threshold autoregressive models. Working Paper Iowa State University, Department of Economics. 1999. 
; GRANGER, C. W. J. Unit root tests and asymmetric adjustment with an example using the term structure of interest rates. Journal of Business \& Economic Statistics, v. 16, n. 3, p. 305-311, 1998.

ENGLE, R. F.; GRANGER, C. W. J. Long-run economic relationship: readings in cointegration. New York: Oxford University Press, 301p, 1987.

GRANGER, C. Investigating causal relations by econometric models and cross-spectral methods. Econometrica, v. 37, n. 3, p. 424-438, 1969.

; TERASVIRTA, T. Modeling nonlinear economic relationships. Oxford University Press. Oxford, UK, 1993.

GUILLÉN, O. T.; VICENTE, J. V.; MORAES, C. O. Análise do comportamento dos bancos brasileiros pré e pós crise subprime. In: ENCONTRO NACIONAL DE ECONOMIA, 40, Porto de Galinhas, 2012. Anais... ANPEC: Porto de Galinhas, Pernambuco, 2012.

ICE - International Exchange. Database. Available in: $<$ https://www.theice.com $>$. Acesso em: 03 jul 2015.

JOHANSEN, S. Estimation and hypothesis testing of cointegration vectors in gaussian vector autoregressive models. Econometrica, v. 59, n. 6, p. 1551-1580, 1991.

KWIATKOWSKI, D.; PHILLIPS, P.; SCHMIDT, P.; SHIN, Y. Testing the null hypothesis of stationary against the alternative of a unit root. Journal of Econometrics, v. 54, p. 159-178, 1992.

MISHRA, V.; SMYTH, R. Are natural gas spot and futures prices predictable? Economic Modelling, v. 54, p. 178-186, 2016.

NICOLAU, M.; PALOMBA, G. Dynamic relationships between spot and futures prices. The case of energy and gold commodities. Resources Policy, v. 45, p. 130-143, 2015.

PESARAN, M. H.; SHIN, Y. Cointegration and speed of convergence to equilibrium. Journal of Econometrics, v. 71, n. 1-2, p. 117-143, 1998.

TILL, H.; EAGLEEYE, J. Challenges in Commodity Risk Management. Commodities Now, p. 45-50, 2009.

Trading Economics. Database. Available in: $<$ http://www.tradingeconomics.com/ $>$. Acesso em 18 mar. 2016. 
